\title{
TAS-102 Independent and Combined Therapy in Metastatic Colorectal Cancer
}

\author{
Cheng-Jiang Liu \\ Anhui Medical University \\ Ting Hu \\ Anhui Medical University \\ Ping Shao \\ Anhui Medical University \\ Wu-Yang Chu \\ Anhui Medical University \\ Yu Cao \\ Anhui Medical University
}

Feng Zhang ( $\sim$ jonathan.cheung@foxmail.com)

Technical University of Munich: Technische Universitat Munchen https://orcid.org/0000-0001-5629-5571

\section{Research Article}

Keywords: colorectal cancer, TAS-102, mOS, mPFS, adverse events

Posted Date: August 24th, 2021

DOI: https://doi.org/10.21203/rs.3.rs-735929/v1

License: (c) (1) This work is licensed under a Creative Commons Attribution 4.0 International License. Read Full License 


\section{Abstract \\ Objective}

To evaluate the effectiveness and safety of TAS-102 in the treatment of metastatic colorectal cancer.

\section{Methods}

The pubmed, web of science, medline, cochrane library databases were searched for the literature on TAS-102 treatment of metastatic colorectal cancer. Extract data such as median Overall Survival (mOS), median Progression-Free Survival (mPFS) and the incidence of adverse events for meta-analysis.

\section{Results}

Our study found that the mOS of patients treated with TAS-102 was 7.74 (95\% Cl: 6.09-9.85) and the mPFS was 2.91 (95\%Cl: 2.38-3.57). The mOS in patients treated by TAS-102 Combined with bevacizumab is 10.41 (95\% Cl: $8.40-12.89)$ and the mPFS is 4.35 ( $95 \% \mathrm{Cl}: 3.05-$ 6.20). In the control experiment, the patients' mOS and mPFS were improved. TAS- $102+B$ VS. TAS- 102 (OR $=0.41,95 \%$ Cl: $0.18-0.93 ;$ OR $=0.72,95 \%$ Cl: $0.63-0.83)$. TAS-102 VS. Placebo(OR $=0.44,95 \%$ Cl: $0.29-0.67 ; \mathrm{OR}=0.51,95 \% \mathrm{Cl}: 0.42-0.62)$. The incidence of adverse events in combination with bevacizumab will increase.

\section{Conclusion}

TAS-102 single or combined treatment can significantly improve the survival of patients, and drug safety should be considered when formulating a combined treatment plan.

\section{Introduction}

By 2020, it is estimated that colorectal cancer is the cause of 935,000 cancer-related deaths worldwide, accounting for $9 \%$ of all cancer deaths ${ }^{1}$. In the initial diagnosis, approximately $25 \%$ of colorectal cancer patients have concurrent metastatic disease, and more than half of the patients are diagnosed as metastases ${ }^{2,3}$. Despite advances in the treatment of metastatic CRC (metastatic colorectal cancer), the survival rate is still poor. And the expected survival period without effective drug treatment is about 6 months $\mathrm{s}^{4-6}$.

TAS-102 (trifluridine/tipiracil) is an oral anticancer drug containing a thymidine analogue (trifluridine). It is composed of active cytotoxic component FTD and effective thymidine phosphorylase inhibitor TPI hydrochloride. The molar ratio is 1:0.5 ${ }^{5}$. FTD is the active cytotoxic component of the drug. TPI can prevent thymidine phosphorylase from rapidly degrading FTD into Inactive form ${ }^{7,8}$. FTD/TPI is established as the third-line treatment for metastatic colorectal cancer. According to the results of the international phase III RECOURSE study, the study reported the significant benefits of FTD/TPI compared with placebo in terms of overall survival (OS), and acceptable security conditions ${ }^{9,10}$.

The efficacy and safety of FTD/TPI monotherapy in adults with refractory mCRC was first demonstrated in a Japanese phase II trial by Yoshino et al. ${ }^{5}$ and later in the pivotal phase III RECOURSE trial ${ }^{4}$. In these two studies, TAS-102 showed good effectiveness, significantly improving overall survival (mOS) and median progression-free survival (mPFS). TAS-102 combined with bevacizumab have a good effectiveness in the treatment of metastatic colorectal cancer, while reducing the incidence of adverse events.

Regorafenib and TAS-102 are both considered as new treatment options for salvage line therapy. A meta-analysis showed similar effectiveness of the two drugs, but the occurrence of adverse events may be different ${ }^{12}$. The main goal of clinical trials is to establish the effectiveness and safety of the drug in a carefully selected group of patients. However, there are still differences from real-world applications. The actual application of TAS-102 needs more attention. This study conducted a meta-analysis of clinical trials in the practical application of TAS-102, and compared the safety and effectiveness of drugs in controlled trials and uncontrolled trials.

\section{Material And Methods}

\subsection{Search Strategy}


PubMed, Medline, Web of Science, Cochrane databases were searched for eligiity publications. The following keywords were used: "metastatic colorectal cancer" AND "TAS-102" OR "FTD/TPI". There is no time limit for searching until the final search date is May 31, 2021. In addition, the reference list of applicable studies was manually checked for inclusion in other articles. Two researchers jointly complete this search process.

\subsection{Inclusion and Exclusion}

These articles are manually screened for relevance, first by removing duplicate publications, and then checking the abstract if the title is not enough to exclude. If a publication appears to meet the inclusion criteria after reading the abstract, it will be marked for full text inspection. Review the design, intervention methods, and results of the study, and evaluate compliance with the requirements. Animal experiments, reviews, reports, non-refractory colorectal cancer, inappropriate outcome indicators, non-compliant intervention are the main exclusion principles.

\subsection{Data Extraction and Quality Assessment}

Two researchers independently extracted relevant information from each study: first author, year of publication, demographic characteristics of participants include age, gender, ECOG performance status, (K) RAS status, grouping scheme, sample size, median os, median pfs, HR, the incidence of grade $\geq 3 \mathrm{AEs}$. We downloaded the full text. If in doubt, ask the original author for help. The NOS scale is used to evaluate the quality of the included controlled trials. The total score is 9 points, and the scores above 5 are included in the metaanalysis. However, for the included one-arm experiment, the first 8 items of the MINORS item were selected for quality evaluation. Each item is 2 points and the total score is 16 points, 10 points or more enter our research.

\subsection{Statistical Analysis}

Based on the recommendations of the Cochrane collaboration, quantitative synthesis of the indicators included in the study. In metaanalysis, $I^{2}>50 \%$ is considered heterogeneous. In the absence of significant heterogeneity, a fixed-effect model is used; otherwise, a random-effect model is used ${ }^{13}$. Performing sensitivity analyze and subgroup analyze for the included studies to find the reason of heterogeneity. Funnel plots were used to detect whether there is a small research effect ${ }^{14}$.

\section{Results}

\subsection{The characteristics of the included studies}

855 studies were retrieved. Two investigators were screened and included 26 studies $4,5,9-11,15-35$. Including 14 controlled experiments and 12 single-arm experiments. The average age of 3780 participants was over 50 years old. The intervention methods are TAS-102 alone or combined with bevacizumab, and the control is (REG)regorafenib or placebo. The search and screening process is described in Fig. 1. All studies included in this study were based on moderate- to high-quality evidence. Table 1 provides a brief description of these 26 studies. In the included studies, the score of the controlled experiment was above 5, and the score of the uncontrolled experiment was above 10 . The quality of the literature can support the meta-analysis. The appendix summarizes the literature quality evaluation situation. 
Table 1

Characteristics of Included Studies

\begin{tabular}{|c|c|c|c|c|c|c|c|c|}
\hline Study & Age(years) & $\begin{array}{l}\text { Sex } \\
\text { male/female }\end{array}$ & $\begin{array}{l}\text { ECOG } \\
\text { performance } \\
\text { status }(0 / \\
\geq 1)\end{array}$ & $\begin{array}{l}\text { KRAS status } \\
\text { Wild/Mutated }\end{array}$ & Methods & Sample & moS(months) & mPFS(months) \\
\hline \multirow{2}{*}{$\begin{array}{l}\text { Mayer et } \\
\text { al, } 2015^{4}\end{array}$} & $63(27-82)$ & $326 / 208$ & $301 / 233$ & $272 / 262$ & TAS-102 & 534 & $7.1(6.5-7.8)$ & $2(1.9-2.1)$ \\
\hline & $63(27-82)$ & $165 / 101$ & $147 / 119$ & $131 / 135$ & Placebo & 266 & $5.3(4.6-6.0)$ & $1.7(1.7-1.8)$ \\
\hline \multirow[t]{2}{*}{$\begin{array}{l}\text { Pfeiffer et } \\
\text { al, } 2020^{15}\end{array}$} & NA & NA & NA & NA & $\begin{array}{l}\text { TAS- } \\
102+B\end{array}$ & 46 & NA & $4.6(3.5-6.5)$ \\
\hline & NA & NA & NA & NA & TAS-102 & 47 & NA & $2.6(1.6-3.5)$ \\
\hline \multirow[t]{2}{*}{$\begin{array}{l}\text { Sueda et } \\
\text { al, } 2016^{16}\end{array}$} & $66(44-80)$ & $10 / 4$ & $1 / 13$ & $9 / 5$ & TAS-102 & 14 & $\begin{array}{l}6.3(3.21- \\
9.93)\end{array}$ & $2.1(0.92-6.39)$ \\
\hline & $59(37-83)$ & $12 / 11$ & $10 / 13$ & $12 / 11$ & REG & 23 & $5.8(3.7-11.7)$ & $3.0(1.64-4.52)$ \\
\hline \multirow{2}{*}{$\begin{array}{l}\text { Masuishi } \\
\text { et al, } \\
2017^{17}\end{array}$} & NA & $30 / 24$ & NA & $21 / 32$ & TAS-102 & 54 & $6.5(5.3-8.3)$ & $2.1(1.8-3.1)$ \\
\hline & NA & $90 / 56$ & NA & $78 / 67$ & REG & 146 & $6.7(5.8-7.6)$ & $2.1(1.8-2.5)$ \\
\hline \multirow{2}{*}{$\begin{array}{l}\text { Makiyama } \\
\text { et al, } \\
2018^{18}\end{array}$} & $66(39-82)$ & $6 / 5$ & $5 / 6$ & NA & $\begin{array}{l}\text { TAS- } \\
102+B\end{array}$ & 11 & Not reach & 5.8 \\
\hline & $69(47-82)$ & $20 / 13$ & $11 / 22$ & NA & TAS-102 & 33 & 6.4 & 1.8 \\
\hline \multirow{2}{*}{$\begin{array}{l}\text { Yoshino et } \\
\text { al, } 2012^{5}\end{array}$} & $>20$ & NA & NA & NA & TAS-102 & 112 & $9.0(7.3-11.3)$ & NA \\
\hline & $>20$ & NA & NA & NA & Placebo & 57 & $6.6(4.9-8.0)$ & NA \\
\hline \multirow{6}{*}{$\begin{array}{l}\text { Cutsem et } \\
\text { al, } 2017^{9}\end{array}$} & $60.2(11.86)$ & $31 / 33$ & $28 / 36$ & $35 / 29$ & TAS-102 & 64 & 6.5 & NA \\
\hline & $58.5(11.02)$ & $18 / 17$ & $13 / 22$ & $17 / 18$ & Placebo & 35 & 4.3 & NA \\
\hline & 61.8(9.98) & $167 / 104$ & $138 / 133$ & $123 / 148$ & TAS-102 & 271 & NA & NA \\
\hline & $62.1(10.42)$ & $82 / 50$ & $68 / 64$ & $68 / 64$ & Placebo & 132 & NA & NA \\
\hline & $61.9(10.09)$ & $113 / 65$ & $128 / 50$ & $94 / 84$ & TAS-102 & 178 & 7.8 & NA \\
\hline & $62.1(10.40)$ & $58 / 30$ & $60 / 28$ & $40 / 48$ & Placebo & 88 & 6.7 & NA \\
\hline \multirow{2}{*}{$\begin{array}{l}\text { Xu et al, } \\
2017^{10}\end{array}$} & $58(26-81)$ & $170 / 101$ & $64 / 207$ & $172 / 99$ & TAS-102 & 271 & $7.8(7.1-8.8)$ & NA \\
\hline & $56(24-80)$ & $84 / 51$ & $30 / 105$ & $85 / 50$ & Placebo & 135 & $7.1(5.9-8.2)$ & NA \\
\hline \multirow{2}{*}{$\begin{array}{l}\text { Longo- } \\
\text { Muñoz et } \\
\text { al, } 2016^{19}\end{array}$} & $\begin{array}{l}61.5(27- \\
81)\end{array}$ & $48 / 32$ & $24 / 56$ & $35 / 45$ & TAS-102 & 80 & 6.8 & 2 \\
\hline & $\begin{array}{l}62.5(39- \\
78)\end{array}$ & $21 / 11$ & $11 / 21$ & $17 / 15$ & Placebo & 32 & 4.6 & 1.7 \\
\hline \multirow{2}{*}{$\begin{array}{l}\text { Moriwaki } \\
\text { et al, } \\
2018^{20}\end{array}$} & $64(29-86)$ & $197 / 130$ & 128/199 & $160 / 161$ & TAS-102 & 327 & $7.4(6.6-8.3)$ & NA \\
\hline & $64(31-84)$ & $126 / 97$ & $95 / 128$ & $88 / 109$ & REG & 223 & $7.9(6.8-9.2)$ & NA \\
\hline \multirow[t]{2}{*}{$\begin{array}{l}\text { Kotani et } \\
\text { al, 201921 }\end{array}$} & $60(23-79)$ & $35 / 25$ & $35 / 25$ & $28 / 32$ & $\begin{array}{l}\text { TAS- } \\
102+B\end{array}$ & 60 & $8.6(6.9-10.3)$ & $3.7(2.3-5.1)$ \\
\hline & $65(30-80)$ & $42 / 24$ & $42 / 24$ & $30 / 36$ & TAS-102 & 66 & $8.0(6.7-9.4)$ & $2.2(1.8-2.6)$ \\
\hline
\end{tabular}




\begin{tabular}{|c|c|c|c|c|c|c|c|c|}
\hline Study & Age(years) & $\begin{array}{l}\text { Sex } \\
\text { male/female }\end{array}$ & $\begin{array}{l}\text { ECOG } \\
\text { performance } \\
\text { status }(0 / \\
\geq 1)\end{array}$ & $\begin{array}{l}\text { KRAS status } \\
\text { Wild/Mutated }\end{array}$ & Methods & Sample & mOS(months) & mPFS(months) \\
\hline \multirow[t]{2}{*}{$\begin{array}{l}\text { Fujii et al, } \\
2020^{11}\end{array}$} & $67(50-74)$ & $13 / 8$ & NA & $10 / 11$ & $\begin{array}{l}\text { TAS- } \\
102+B\end{array}$ & 21 & 14.4(7.9-NA) & NA \\
\hline & $\begin{array}{l}\text { 67.5(59.8- } \\
71.2)\end{array}$ & $16 / 20$ & NA & $16 / 20$ & TAS-102 & 36 & $4.5(3.2-6.5)$ & NA \\
\hline \multirow{2}{*}{$\begin{array}{l}\text { Ogata et } \\
\text { al, } 2020^{22}\end{array}$} & $68(40-85)$ & $38 / 39$ & $35 / 42$ & $53 / 24$ & TAS-102 & 77 & 11.4 & 3.3 \\
\hline & $66(41-81)$ & $30 / 27$ & $30 / 27$ & $36 / 21$ & REG & 57 & 9.9 & 2 \\
\hline \multirow[t]{2}{*}{$\begin{array}{l}\text { Nose et al, } \\
2020^{23}\end{array}$} & $73(49-90)$ & $16 / 16$ & $12 / 20$ & $14 / 17$ & $\begin{array}{l}\text { TAS- } \\
102+B\end{array}$ & 32 & 11.7 & 4.7 \\
\hline & $\begin{array}{l}70.5(43- \\
88)\end{array}$ & $15 / 9$ & $7 / 17$ & $14 / 10$ & TAS-102 & 24 & 6.3 & 1.8 \\
\hline $\begin{array}{l}\text { Cicero et } \\
\text { al, } 2020^{24}\end{array}$ & $78(70-86)$ & $28 / 22$ & $18 / 32$ & $18 / 22$ & TAS-102 & 50 & $6.7(5.7-11.3)$ & $2.1(1.2-3.2)$ \\
\hline $\begin{array}{l}\text { Cecchini } \\
\text { et al, } \\
2021^{25}\end{array}$ & NA & NA & NA & NA & TAS-102 & 41 & $6.8(5.7-10)$ & $2.7(2.4-4.8)$ \\
\hline $\begin{array}{l}\text { Sforza et } \\
\text { al, } 2017^{26}\end{array}$ & $65(48-82)$ & $31 / 12$ & $27 / 16$ & $16 / 27$ & TAS-102 & 43 & $6.6(2.8-10.4)$ & $2.8(2.5-3.1)$ \\
\hline $\begin{array}{l}\text { Montes et } \\
\mathrm{al}, 2020^{27}\end{array}$ & $63(37-83)$ & $108 / 52$ & $18 / 142$ & $57 / 103$ & TAS-102 & 160 & $\begin{array}{l}7.64(6.15- \\
9.13)\end{array}$ & $\begin{array}{l}2.75(2.57- \\
2.94)\end{array}$ \\
\hline $\begin{array}{l}\text { Oki et al, } \\
2021^{28}\end{array}$ & $76(70-88)$ & $15 / 22$ & $23 / 14$ & $10 / 21$ & TAS-102 & 37 & $\begin{array}{l}22.4(17.3- \\
35.1)\end{array}$ & $9.4(7.2-11.6)$ \\
\hline $\begin{array}{l}\text { Takahashi } \\
\text { et al, } \\
2021^{29}\end{array}$ & $73(65-81)$ & $21 / 9$ & NA & NA & TAS-102 & 30 & $5.7(3.7-8.9)$ & $2.3(1.9-4.3)$ \\
\hline $\begin{array}{l}\text { Kwakman } \\
\text { et al, } \\
2018^{30}\end{array}$ & $62(30-88)$ & $92 / 44$ & $46 / 90$ & $53 / 83$ & TAS-102 & 136 & $5.4(4.0-6.9)$ & $2.1(1.8-2.3)$ \\
\hline $\begin{array}{l}\text { Moehler et } \\
\text { al, } 2021^{31}\end{array}$ & $60(35-78)$ & $6 / 6$ & $6 / 6$ & NA & TAS-102 & 12 & $\begin{array}{l}11.1(2.3- \\
18.2)\end{array}$ & $\begin{array}{l}3.81(1.51- \\
5.29)\end{array}$ \\
\hline $\begin{array}{l}\text { Yoshida et } \\
\text { al, } 2020^{32}\end{array}$ & $67(45-78)$ & $20 / 12$ & $23 / 9$ & $14 / 18$ & $\begin{array}{l}\text { TAS- } \\
102+B\end{array}$ & 32 & $9.2(5.5-12.8)$ & $4.5(1.8-7.1)$ \\
\hline $\begin{array}{l}\text { Wallander } \\
\text { et al, } \\
2020^{33}\end{array}$ & $65(38-78)$ & $28 / 20$ & $13 / 34$ & $17 / 29$ & TAS-102 & 48 & $6.4(4.4-8.4)$ & $2.3(1.8-2.7)$ \\
\hline $\begin{array}{l}\text { Satake et } \\
\mathrm{al}, 2020^{34}\end{array}$ & $69(33-82)$ & $24 / 20$ & $25 / 19$ & $25 / 19$ & $\begin{array}{l}\text { TAS- } \\
102+B\end{array}$ & 44 & $\begin{array}{l}10.86(8.32- \\
13.68\end{array}$ & $\begin{array}{l}4.29(2.54- \\
5.83)\end{array}$ \\
\hline $\begin{array}{l}\text { Carries et } \\
\mathrm{al}, 2019^{35}\end{array}$ & $\begin{array}{l}65.29(40- \\
88)\end{array}$ & 49/35 & $13 / 71$ & $31 / 53$ & TAS-102 & 84 & $\begin{array}{l}8.3(6.23- \\
9.87)\end{array}$ & $\begin{array}{l}2.62(2.32- \\
3.05)\end{array}$ \\
\hline
\end{tabular}

\subsection{Effectiveness of uncontrolled clinical trials}

Pooling the PFS data from 12 uncontrolled clinical trials revealed that the mOS of patients with metastatic colorectal cancer was 8.11 ( $95 \% \mathrm{Cl}: 6.57-10.01)$. A random effect model was used, $\mathrm{I}^{2}=79.7 \%$ (Fig. 2). Subgroup analysis showed that the mOS of TAS-102 combined with bevacizumab treatment may be higher. TAS-102 + B: mOS $=10.41(95 \% \mathrm{Cl}: 8.40-12.89)$, TAS-102: $\mathrm{mOS}=7.74$ (95\%Cl: 6.09-9.85). A sensitivity analysis that eliminated studies one by one did not detect abnormalities. The funnel chart and Begg's test (Egger's test) show that there is no publication bias. 
Similarly, the mPFS of patients was 3.06 ( $95 \% \mathrm{Cl}$ : 2.52-3.70). A random effect model was used, $\mathrm{I}^{2}=91.8 \%$ (Fig. 3). Subgroup analysis did not find a difference between TAS-102 + B and TAS-102 alone. TAS-102 + B: mPFS = 4.35 (95\%Cl: 3.05-6.20), TAS-102: $\mathrm{mPFS}=2.91$ (95\% Cl: 2.38-3.57). A sensitivity analysis that eliminated studies one by one did not detect abnormalities. The funnel chart and Begg's test (Egger's test) show that there is no publication bias.

\subsection{Effectiveness and safety of controlled clinical trials}

16 clinical controlled trials were included. Divided into two designs (TAS-102 + B VS. TAS-102 AND TAS-102 VS. Placebo). Under the first scheme, compared with the control group, the mOS was improved, and the risk ratio of death was 0.41 (95\% $\mathrm{Cl}: 0.18-0.93)$. A random effect model was used, $\mathrm{I}^{2}=73.0 \%$ (Fig. 4). Similarly, the mOS death hazard ratio in the second scheme was 0.72 (95\% Cl: 0.63-0.83). A random effect model was used, $\mathrm{I}^{2}=58.7 \%$ (Fig. 4). A sensitivity analysis that eliminated studies one by one did not detect abnormalities. The funnel chart and Begg's test (Egger's test) show that there is no publication bias.

Under the first scheme, compared with the control group, the mPFS was improved, and the risk ratio of death was 0.44 ( $95 \%$ Cl: $0.29-0.67)$. A random effect model was used, $I^{2}=60.9 \%$ (Fig. 5). Similarly, the mPFS death hazard ratio in the second scheme was 0.51 (95\% Cl: $0.42-$ 0.62). A random effect model was used, $I^{2}=52.8 \%$ (Fig. 5). A sensitivity analysis that eliminated studies one by one did not detect abnormalities. The funnel chart and Begg's test (Egger's test) show that there is no publication bias.

9 studies showed the incidence of grade $\geq 3 \mathrm{AEs}$ in the experimental group and the control group. Compared with the placebo group, there is no difference in safety under the treatment of TAS-102 alone. $\mathrm{OR}=3.10(95 \% \mathrm{Cl}: 0.88-10.87)$. Random effects model was used, $\mathrm{I}^{2}=$ 84.7\% (Fig. 6). Compared with the application of TAS-102 alone, the combination of bevacizumab may increase the incidence of adverse events. $\mathrm{OR}=2.19(95 \% \mathrm{Cl}: 1.40-3.44)$. The fixed effects model is applied, $\mathrm{I}^{2}=0.0 \%$ (Fig. 6). A sensitivity analysis that eliminated studies one by one did not detect abnormalities. The funnel chart and Begg's test (Egger's test) show that there is no publication bias.

\section{Discussion}

Almost $55 \%$ of colorectal cancer cases worldwide occur in more developed countries. Its incidence continues to rise in developing countries $^{36}$. As with most cancer types, surgery is the main treatment method. For metastatic cancer, cytotoxic methods, such as neoadjuvant therapy and adjuvant therapy, are used before or after it. The main treatment options include fluoropyrimidine, oxaliplatin, and irinotecan. TAS-102 is an anti-cancer drug that has entered people's field of vision in recent years. Because of its excellent clinical efficacy and safety, it is often added to the treatment of colorectal cancer, gastric cancer in the middle and late stages and anti-cancer treatment programs for metastatic tumors.

Our study found that the mOS of patients treated with TAS-102 was 7.74 (95\%Cl: $6.09-9.85)$ and the mPFS was 2.91 (95\%Cl: 2.38-3.57). The mOS in patients treated by TAS-102 combined with bevacizumab is 10.41 (95\% Cl: $8.40-12.89)$ and the mPFS is 4.35 (95\% $\mathrm{Cl}: 3.05-$ 6.20). Combination therapy may have better effectiveness. As the current targeted drug for the treatment of metastatic colorectal cancer, it is a humanized monoclonal antibody against vascular endothelial growth factor (VEGF), which plays an anti-tumor effect by blocking the formation of tumor blood vessels and regulating the immune function of patients ${ }^{37}$. In 2004, the FDA approved bevacizumab combined with chemotherapy drugs as the first-line treatment for mCRC. A study showed that bevacizumab combined with first-line chemotherapy for metastatic colorectal cancer can significantly prolong the survival and PFS of patients with $\mathrm{MCRC}$, improve the quality of life, increase the resectable rate of metastases, and improve the survival outcome of patients with $\mathrm{mCRC}^{38,39}$. The number of adverse events has also been significantly reduced.

Although uncontrolled trials can observe the survival of patients, they cannot specify the improvement in survival. We included 16 studies that included two controlled protocols (TAS-102 + B VS. TAS-102 AND TAS-102 VS. Placebo). In either scenario, we found a significant increase in mOS and mPFS. Surprisingly, we found that TAS-102 combined with bevacizumab will increase the incidence of grade $\geq 3$ AES $(\mathrm{OR}=2.19,95 \% \mathrm{Cl}: 1.40-3.44)$ compared to TAS-102 alone. The safety of bevacizumab is worthy of further consideration. This indicates that clinicians need to make careful decisions when making treatment options for patients with metastatic colorectal cancer, considering the patient's tolerance to anticancer drugs.

It is necessary to optimize the design plan when evaluating the efficacy of new drugs. Randomized controlled trials such as resource and TERRA are conducted in homogeneous populations, which can minimize the risk of bias ${ }^{40}$. In the current study, we have included real observational studies aimed at evaluating the effectiveness of a relatively small homogeneous population. These studies have the shortcomings of non-randomized controlled studies. The studies we included included controlled and uncontrolled experiments. And the demographic characteristics and disease manifestations of the participants in the experiment are also quite different. This will actually 
affect the accuracy of our final results. Therefore, more rigorous and appropriate randomized controlled experiments need to be proposed. The published meta-analysis of TAS-102 involves comparison of the effectiveness and safety of multiple therapeutic drugs ${ }^{40-45}$. Regorafenib, TAS-102, fruquintinib, panitumumab and cetuximab are recommended single-agent chemotherapy regimens for patients exhibiting disease progression. The safety of these drugs is difficult to assess. But the safety of the drug does affect the confidence of patients in the treatment plan. The most important thing is the improvement of symptoms and the management of side effects ${ }^{47,48}$.

In a retrospective study, potential predictive or prognostic biomarkers for the efficacy of regorafenib were evaluated ${ }^{46}$. The results indicate that the mutation status of KRAS and PIK3CA may be a predictor of the clinical benefit of regorafenib treatment. However, no biomarkers have been found to predict the efficacy and safety of TAS-102. The frequency of KRAS mutations should be worth exploring, because mOS and mPFS are independent of KRAS status in resource and TERRA, but are highly dependent on KRAS mutations in the second phase of trials in Japan ${ }^{5}$.

Although this study gives the survival status of TAS-102 as a single treatment, it is worth looking forward to the application of the drug combination program may further improve the efficacy of FTD/TPI, and some clinical trials are currently underway.

\section{Declarations}

\section{Disclosure:}

Approval of the research protocol: N/A

Informed Consent: N/A

Registry and the Registration No. of the study/Trial: N/A

Animal Studies: N/A

Conflict of Interest: N/A

\section{Conflict of interest statement:}

The authors have declared that no conflict of interest exists.

\section{Author Contributions Statement:}

Cheng-Jiang Liu and Ting Hu wrote the main manuscript text, Ping Shao prepared the tables, Wu-Yang Chu and Yu Cao prepared the figures and Feng Zhang reviewed, revised and polished the article.

\section{References}

1. World Health Organization. Global Cancer Observatory. (2021). https://gco.iarc.fr/Google Scholar.

2. Lim HJ, Gill S, Speers C, et al. Impact of irinotecan and oxaliplatin on overall survival in patients with metastatic colorectal cancer: a population-based study. J Oncol Pract. 2009;5:153-8.

3. Van Cutsem E, Cervantes A, Nordlinger B, et al. Metastatic colorectal cancer: ESMO Clinical Practice Guidelines for diagnosis, treatment and follow-up. Ann Oncol. 2014;25:iii1-9.

4. Mayer RJ, Van Cutsem E, Falcone A, et al. Randomized trial of TAS-102 for refractory metastatic colorectal cancer. N Engl J Med. 2015 May 14;372(20):1909-19.

5. Yoshino T, Mizunuma N, Yamazaki K, et al. TAS-102 monotherapy for pretreated metastatic colorectal cancer: a double-blind, randomised, placebo- controlled phase 2 trial. Lancet Oncol. 2012 Oct;13(10):993-1001.

6. Hoyle M, Peters J, Crathorne L, et al. Cost-effectiveness of cetuximab, cetuximab plus irinotecan, and panitumumab for third and further lines of treatment for KRAS wild-type patients with metastatic colorectal cancer. Value Health. 2013 Mar-Apr;16(2):288-96.

7. Emura T, Murakami Y, Nakagawa F, et al. A novel antimetabolite, TAS-102 retains its effect on FU-related resistant cancer cells. Int $\mathrm{J}$ Mol Med. 2004;13(4):545-549.

8. Emura T, Suzuki N, Yamaguchi M, et al. A novel combination antimetabolite, TAS-102, exhibits antitumor activity in FU-resistant human cancer cells through a mechanism involving FTD incorporation in DNA. Int J Oncol. 2004;25(3):571-578. 
9. Van Cutsem E, Mayer RJ, Laurent S, et al. The subgroups of the phase III RECOURSE trial of trifluridine/tipiracil (TAS-102) versus placebo with best supportive care in patients with metastatic colorectal cancer. Eur J Cancer. 2018 Feb;90:63-72.

10. Xu J, Kim TW, Shen L, et al. Results of a Randomized, Double-Blind, Placebo-Controlled, Phase III Trial of Trifluridine/Tipiracil (TAS102) Monotherapy in Asian Patients With Previously Treated Metastatic Colorectal Cancer: The TERRA Study. J Clin Oncol. 2018 Feb 1;36(4):350-358.

11. Fujii H, Matsuhashi N, Kitahora M, et al. Bevacizumab in Combination with TAS-102 Improves Clinical Outcomes in Patients with Refractory Metastatic Colorectal Cancer: A Retrospective Study. Oncologist. 2020 Mar;25(3):e469-76.

12. Andersen SE, Andersen IB, Jensen BV, et al. A systematic review of observational studies of trifluridine/tipiracil (TAS-102) for metastatic colorectal cancer. Acta Oncol. 2019 Aug;58(8):1149-57.

13. MANTEL N, HAENSZEL W. Statistical aspects of the analysis of data from retrospective studies of disease. J Natl Cancer Inst. 1959 Apr;22(4):719-48.

14. Irwig L, Macaskill P, Berry G, et al. Bias in meta-analysis detected by a simple, graphical test. Graphical test is itself biased. BMJ. 1998 Feb 7;316(7129):470; author reply 470-1.

15. Pfeiffer P, Yilmaz M, Möller S, et al. TAS-102 with or without bevacizumab in patients with chemorefractory metastatic colorectal cancer: an investigator-initiated, open-label, randomised, phase 2 trial. Lancet Oncol. 2020 Mar;21(3):412-20.

16. Sueda T, Sakai D, Kudo T, et al. Efficacy and Safety of Regorafenib or TAS-102 in Patients with Metastatic Colorectal Cancer Refractory to Standard Therapies. Anticancer Res. 2016 Aug;36(8):4299-306.

17. Masuishi T, Taniguchi H, Hamauchi S, et al. Regorafenib Versus Trifluridine/Tipiracil for Refractory Metastatic Colorectal Cancer: A Retrospective Comparison. Clin Colorectal Cancer. 2017 Jun;16(2):e15-22.

18. Makiyama A, Yamaga S, Hirano G, et al. A retrospective study to compare TAS-102 with TAS-102 + BV in advanced colorectal cancer refractory to standard therapy. Ann Oncol. 2018 Oct;29(7):p2-096.

19. Longo-Muñoz F, Argiles G, Tabernero J, et al. Efficacy of trifluridine and tipiracil (TAS-102) versus placebo, with supportive care, in a randomized, controlled trial of patients with metastatic colorectal cancer from Spain: results of a subgroup analysis of the phase 3 RECOURSE trial. Clin Transl Oncol. 2017 Feb;19(2):227-35.

20. Moriwaki T, Fukuoka S, Taniguchi H, et al. Propensity Score Analysis of Regorafenib Versus Trifluridine/Tipiracil in Patients with Metastatic Colorectal Cancer Refractory to Standard Chemotherapy (REGOTAS): A Japanese Society for Cancer of the Colon and Rectum Multicenter Observational Study. Oncologist. 2018 Jan;23(1):7-15.

21. Kotani D, Kuboki Y, Horasawa S, et al. Retrospective cohort study of trifluridine/tipiracil (TAS-102) plus bevacizumab versus trifluridine/tipiracil monotherapy for metastatic colorectal cancer. BMC Cancer. 2019 Dec 27;19(1):1253.

22. Ogata M, Kotaka M, Ogata T, et al. Regorafenib vs trifluridine/tipiracil for metastatic colorectal cancer refractory to standard chemotherapies: A multicenter retrospective comparison study in Japan. PLoS One. 2020 Jun 12;15(6):e0234314.

23. Nose Y, Kagawa Y, Hata T, et al. Neutropenia is an indicator of outcomes in metastatic colorectal cancer patients treated with FTD/TPI plus bevacizumab: a retrospective study. Cancer Chemother Pharmacol. 2020 Sep;86(3):427-33.

24. Cicero G, Addeo R, De Luca R, et al. TAS-102 in metastatic colorectal cancer (mCRC): efficacy, tolerability, and quality of life in heavily pretreated elderly patients: a real-life study. Drugs Context. 2020 Sep 18;9:2020-6-3.

25. Cecchini M, Kortmansky JS, Cui C, et al. A phase 1b expansion study of TAS-102 with oxaliplatin for refractory metastatic colorectal cancer. Cancer. 2021 May 1;127(9):1417-1424.

26. Sforza V, Martinelli E, Cardone C, et al. Clinical outcome of patients with chemorefractory metastatic colorectal cancer treated with trifluridine/tipiracil (TAS-102): a single Italian institution compassionate use programme. ESMO Open. 2017 Sep 21;2(4):e000229.

27. Fernandez Montes A, Vazquez Rivera F, Martinez Lago N, et al. Efficacy and safety of trifluridine/tipiracil in third-line and beyond for the treatment of patients with metastatic colorectal cancer in routine clinical practice: patterns of use and prognostic nomogram. Clin Transl Oncol. 2020 Mar;22(3):351-9.

28. Oki E, Makiyama A, Miyamoto Y, et al. Trifluridine/tipiracil plus bevacizumab as a first-line treatment for elderly patients with metastatic colorectal cancer (KSCC1602): A multicenter phase II trial. Cancer Med. 2021 Jan;10(2):454-61.

29. Takahashi M, Sakamoto Y, Ohori H, et al. Phase II study of trifluridine/tipiracil (TAS-102) therapy in elderly patients with colorectal cancer (T-CORE1401): geriatric assessment tools and plasma drug concentrations as possible predictive biomarkers. Cancer Chemother Pharmacol. 2021 May 24.

30. Kwakman JJM, Vink G, Vestjens JH, et al. Feasibility and effectiveness of trifluridine/tipiracil in metastatic colorectal cancer: real-life data from The Netherlands. Int J Clin Oncol. 2018 Jun;23(3):482-9. 
31. Moehler M, Michel M, Stein A, et al. A Phase I dose-escalation study of third-line regorafenib with trifluridine/tipiracil in metastatic colorectal cancer. Future Oncol. 2021 May 17.

32. Yoshida Y, Yamada T, Kamiyama H, et al. Combination of TAS-102 and bevacizumab as third-line treatment for metastatic colorectal cancer: TAS-CC3 study. Int J Clin Oncol. 2021 Jan;26(1):111-7.

33. Wallander M, Rolander B, Åvall-Lundqvist E, et al. Real world aspects of palliative trifluridine plus tiperacil (TAS-102) in refractory metastatic colorectal cancer. J Gastrointest Oncol. 2020 Aug;11(4):616-25.

34. Satake H, Kato T, Oba K, et al. Phase Ib/II Study of Biweekly TAS-102 in Combination with Bevacizumab for Patients with Metastatic Colorectal Cancer Refractory to Standard Therapies (BiTS Study). Oncologist. 2020 Dec;25(12):e1855-63.

35. Carriles C, Jimenez-Fonseca P, Sánchez-Cánovas M, et al. Trifluridine/Tipiracil (TAS-102) for refractory metastatic colorectal cancer in clinical practice: a feasible alternative for patients with good performance status. Clin Transl Oncol. 2019 Dec;21(12):1781-5.

36. Favoriti P, Carbone G, Greco M, et al. Worldwide burden of colorectal cancer: a review. Updates Surg. 2016;68:7-11.

37. Goey KKH, Elias SG, van Tinteren $\mathrm{H}$, et al. Maintenance treatment with capecitabine and bevacizumab versus observation in metastatic colorectal cancer: updated results and molecular subgroup analyses of the phase 3 CAIRO3 study. Ann Oncol. 2017 Sep 1;28(9):2128-2134.

38. Xiong L, Lou Y, Wang L. Effect of bevacizumab combined with first-line chemotherapy on metastatic colorectal cancer. Am J Transl Res. 2021 Apr 15;13(4):3609-3617.

39. Chida K, Kotani D, Nakamura Y, et al. Efficacy and safety of trifluridine/tipiracil plus bevacizumab and trifluridine/tipiracil or regorafenib monotherapy for chemorefractory metastatic colorectal cancer: a retrospective study. Ther Adv Med Oncol. 2021 Apr;20:13:17588359211009143.

40. Andersen SE, Andersen IB, Jensen BV, et al. A systematic review of observational studies of trifluridine/tipiracil (TAS-102) for metastatic colorectal cancer. Acta Oncol. 2019 Aug;58(8):1149-57.

41. Walter T, Hawkins NS, Pollock RF, et al. Systematic review and network meta-analyses of third-line treatments for metastatic colorectal cancer. J Cancer Res Clin Oncol. 2020 Oct;146(10):2575-87.

42. Su GL, Wang YY, Wang JC, et al. A meta-analysis comparing regorafenib with TAS-102 for treating refractory metastatic colorectal cancer. J Int Med Res. 2020 Jul;48(7):300060520926408.

43. Cao M, Zhou M, Zhang J. Comparison of efficacy and safety for patients with beyond second line treated metastatic colorectal cancer: a network meta-analysis of randomized controlled trials. J Chemother. 2020 Jul;32(4):163-70.

44. Zhang Q, Wang Q, Wang X, et al Regorafenib. TAS-102, or fruquintinib for metastatic colorectal cancer: any difference in randomized trials? Int J Colorectal Dis. 2020 Feb;35(2):295-306.

45. Chen J, Wang J, Lin H, et al. Comparison of Regorafenib, Fruquintinib, and TAS-102 in Previously Treated Patients with Metastatic Colorectal Cancer: A Systematic Review and Network Meta-Analysis of Five Clinical Trials. Med Sci Monit. 2019 Dec 2;25:9179-9191.

46. Ruddy K, Mayer E, Partridge A. Patient adherence and persistence with oral anticancer treatment. CA Cancer J Clin. 2009;59:56-66.

47. Strumberg D, Scheulen ME, Schultheis B, et al. Regorafenib (BAY 73-4506) inadvanced colorectal cancer: a phase I study. Br J Cancer. 2012;106:1722-7.

48. Yoshino T, Komatsu Y, Yamada Y, et al. Randomized phase III trial of regorafenib inmetastatic colorectal cancer: analysis of the CORRECT Japanese and non-Japanese subpopulations. Invest New Drugs. 2015;33:740-50.

\section{Figures}




\section{Identification of studies via databases}
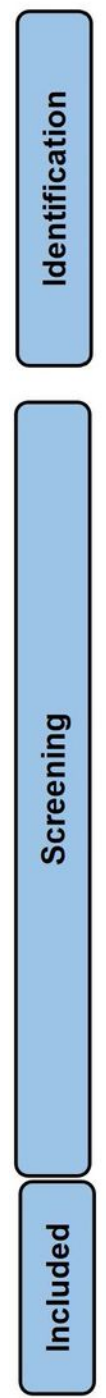

\begin{tabular}{|c|c|}
\hline $\begin{array}{l}\text { Records identified from: } \\
\text { Pubmed }(n=201) \\
\text { Medline }(n=187) \\
\text { Web of science }(n=347) \\
\text { Cochrane library }(n=120)\end{array}$ & $\begin{array}{l}\text { Records removed before } \\
\text { screening: } \\
\text { Duplicate records removed } \\
\quad(n=225)\end{array}$ \\
\hline
\end{tabular}
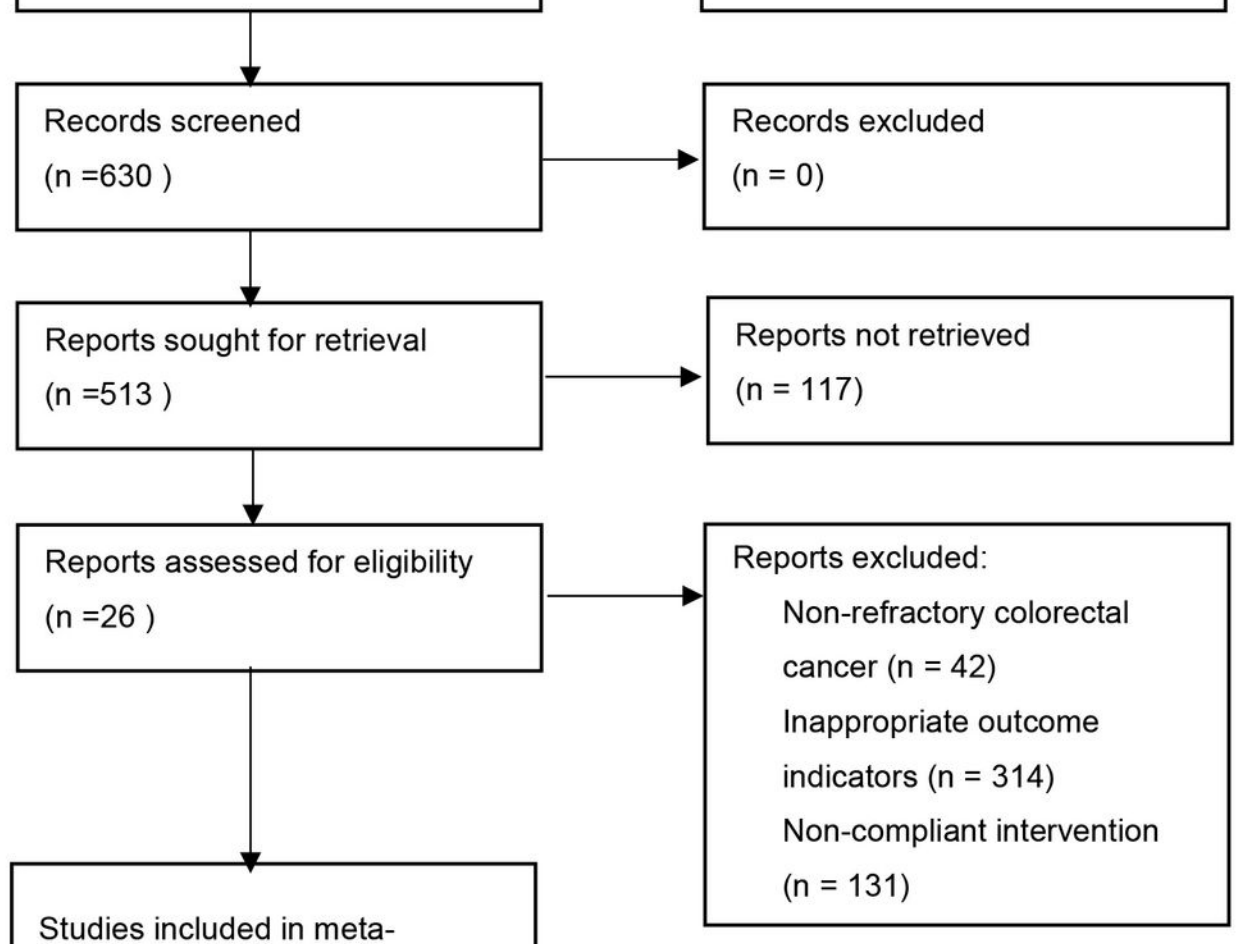

Figure 1

Flow Disgram Showing the Search and Screening Process 
$\operatorname{mOS}(95 \% \mathrm{Cl}) \quad$ Weight

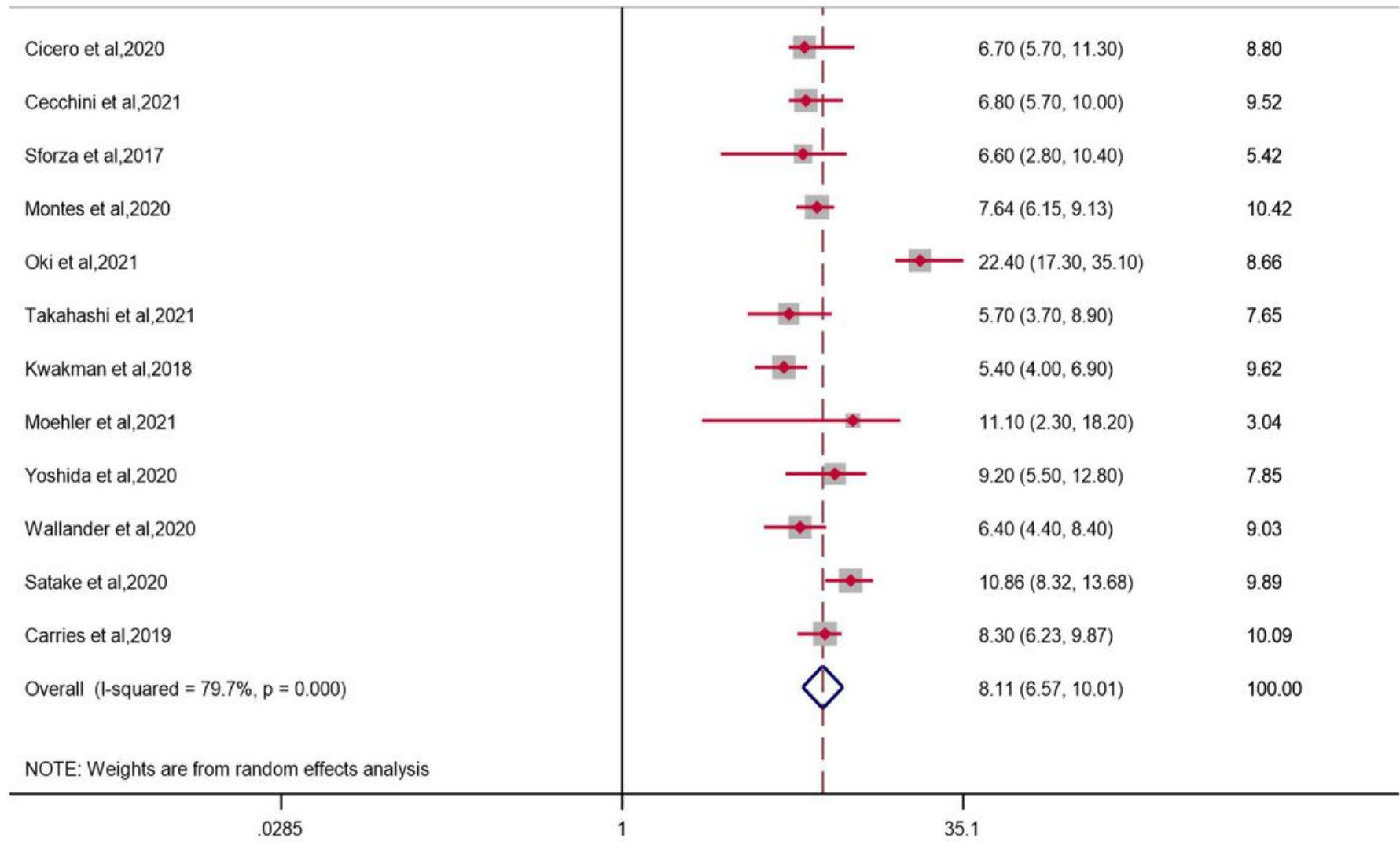

\section{Figure 2}

mOS in Patients with Metastatic Colorectal Cancer Treated with TAS-102 
Study

ID

$\operatorname{mPFS}(95 \% \mathrm{Cl}) \quad$ Weight

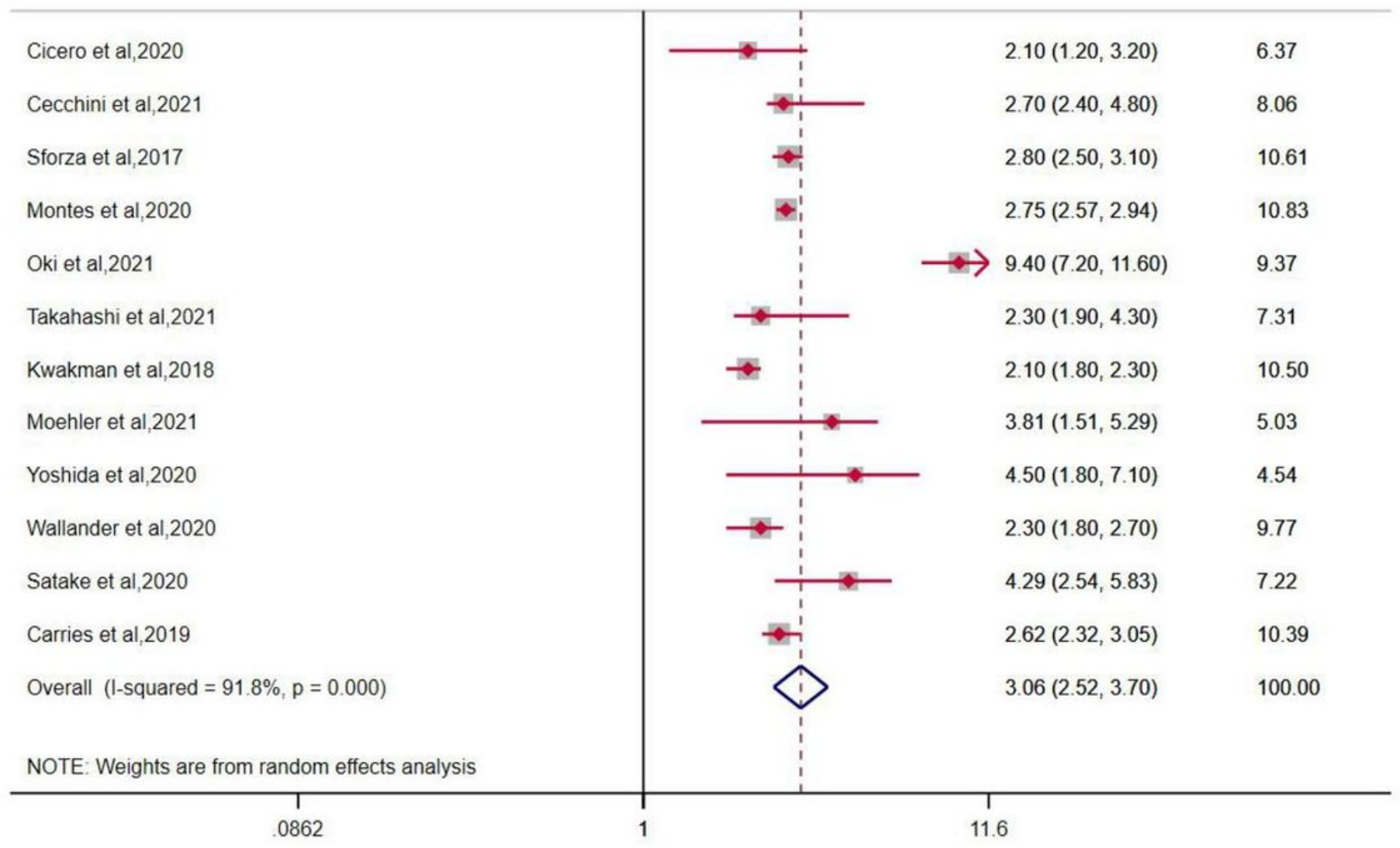

\section{Figure 3}

mPFS in Patients with Metastatic Colorectal Cancer Treated with TAS-102 
Study

10

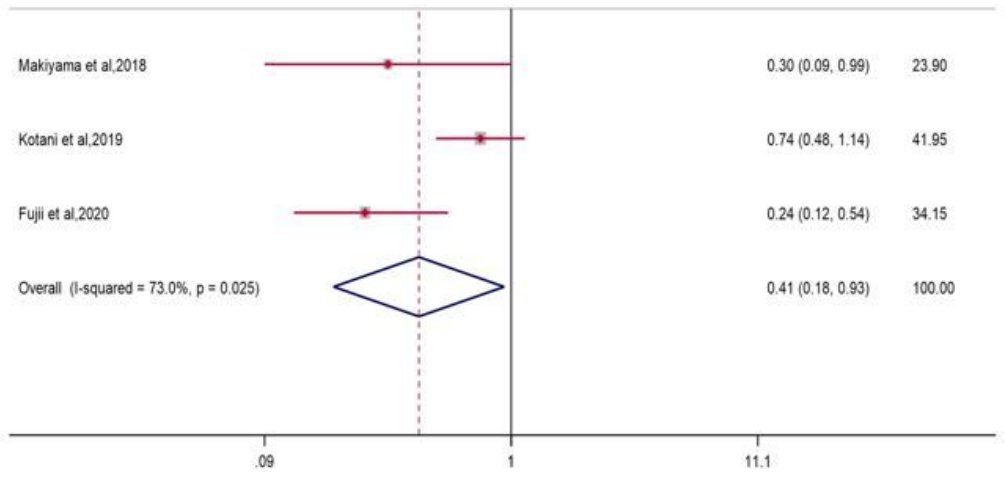

Study

ID

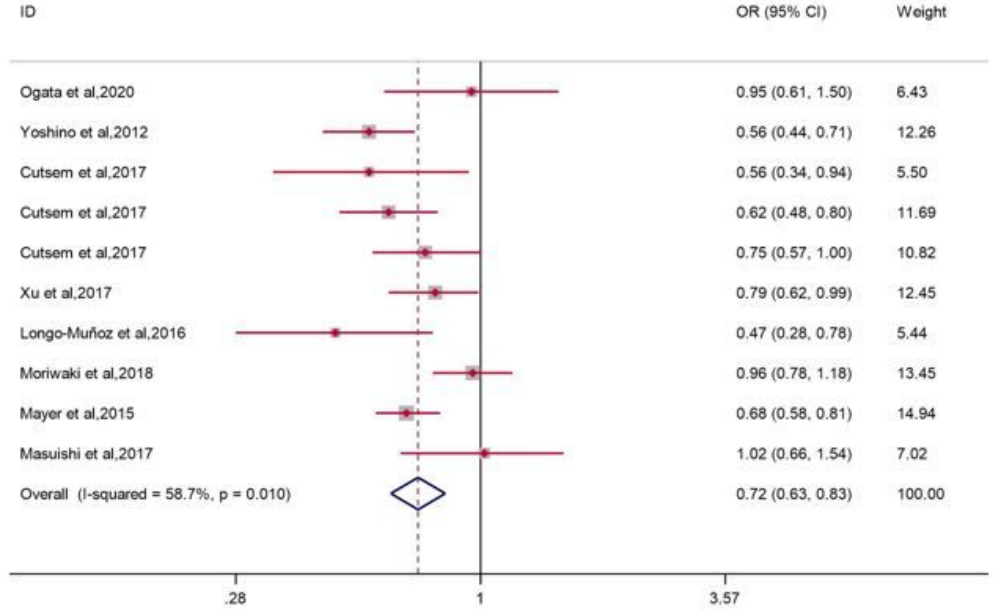

\section{Figure 4}

The Odds Ratio of mOS under TAS-102 Combination and Monotherapy 
Study

ID

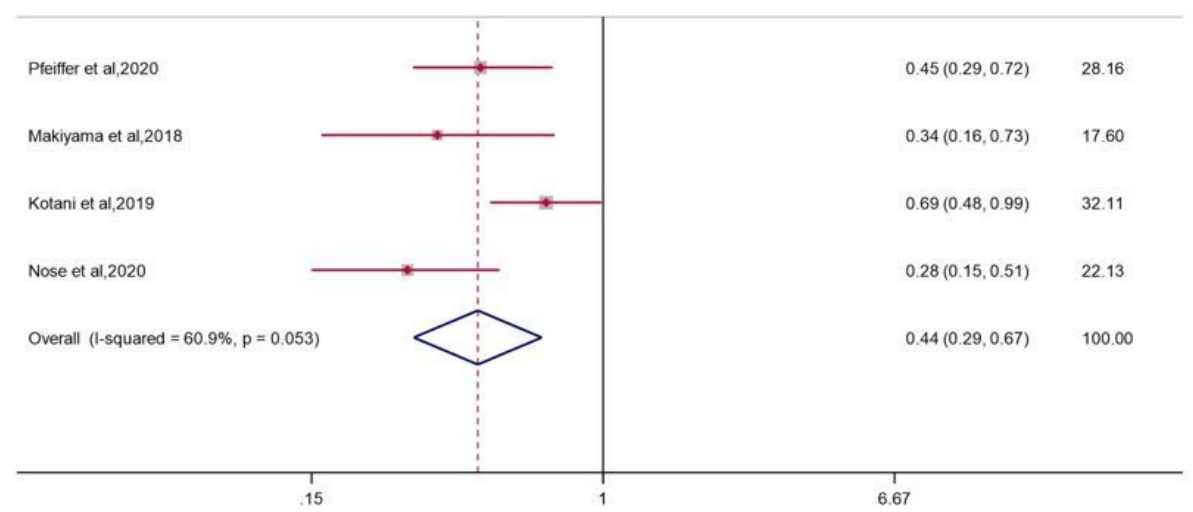

Study

ID

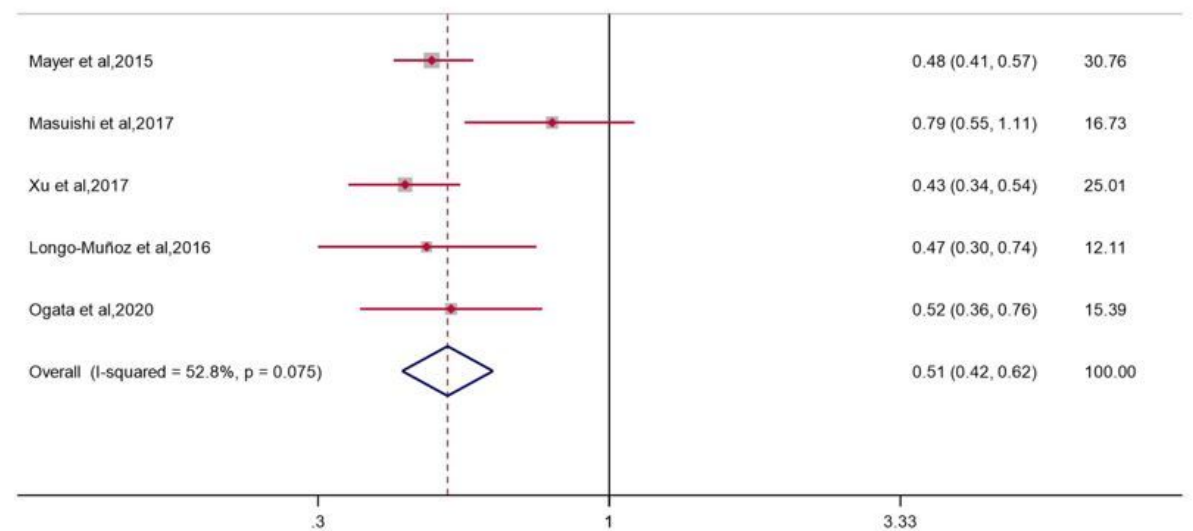

\section{Figure 5}

The Odds Ratio of mPFS under TAS-102 Combination and Monotherapy 


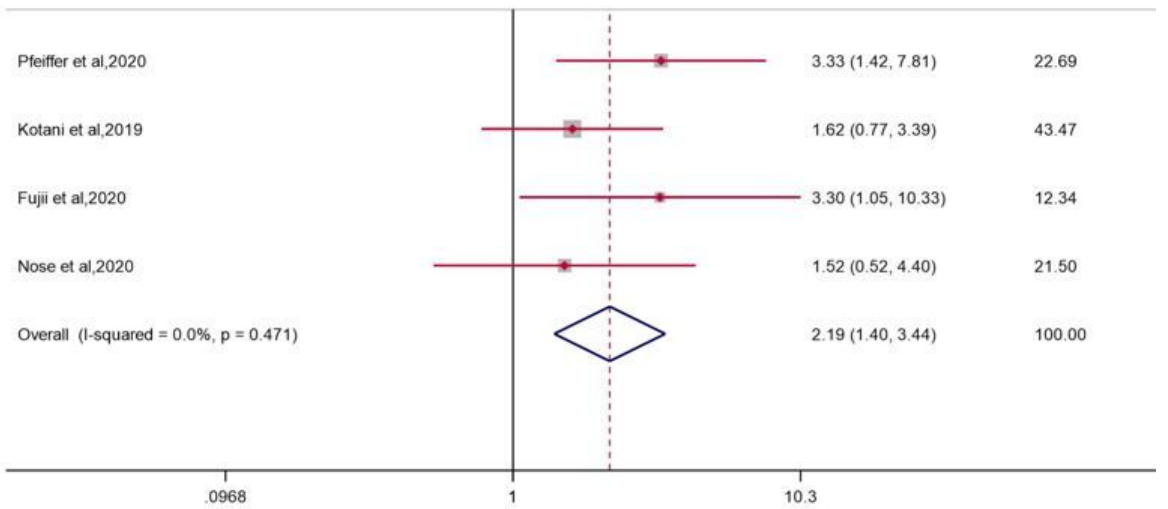

\section{Figure 6}

The Odds Ratio of Incidence of Grade $\geq 3$ AEs under TAS-102 Combination and Monotherapy

\section{Supplementary Files}

This is a list of supplementary files associated with this preprint. Click to download.

- Appendix.docx 